\title{
Algorithms of analogy-based metaphorical coinages in Modern English
}

\author{
Elena Ryzhkina ${ }^{1 *}$ \\ ${ }^{1}$ Moscow State Linguistic University, Russian Federation, 38, Ostozhenka St, Moscow, 119034, \\ Russian Federation
}

\begin{abstract}
The research looks into the phenomenon of analogy as a key cognitive-linguistic mechanism that provides the systematic quality of the creative functioning of linguistic units. Specifically, the study examines analogy-based English metaphorical neologisms. Apart from sampling, semantic and conceptual analyses, the research also applies methods and techniques proposed by corpus linguistics and construction grammar. The work proceeds from the assumption that, while creating novel expressions by analogy with a conventional one, the speaker relies on a relative similarity of two concepts, which makes it possible to represent one of them through the other by modifying and adjusting the latter in accordance with the speaker's intent. At the linguistic level, this kind of modification is reflected in the variation of the lexical components of the linguistic prototype used by the speaker as a model for forming new units. However, a corpus-based study into the functioning of the selected units shows that the construction of the prototype normally remains intact throughout the whole range of lexical change the initial expression undergoes. The constancy of the prototype's construction and clear algorithm-like patterns involved in creating analogical units account for the fact that new coinages are easily recognized and their meaning adequately deciphered.
\end{abstract}

\section{Introduction}

The work sums up the results of a research into the particulars of coining new lexical units by analogy in Modern English. To be more exact, the research aims to examine the mechanism of analogy involved in creating novel metaphorical expressions that accounts for their systematicity and transparency.

Although the problem discussed seems to belong to a well-elabourated area of linguistic studies, the present research brings into focus some aspects that are fairly little covered in literature.

\footnotetext{
*Corresponding author: phraseologinya@mail.ru
} 


\subsection{Assumptions}

The problem of renovating language, especially its lexical system, has long aroused interest in scholars of all times - since antiquity. In the Russian linguistic tradition, the major (and earliest) works on language/lexical creativity or creative use of nominative units are associated with the names of Alexander Potebnya and Jan Baudouin de Courtenay. The latter was the first to clearly formulate the idea of a complementary unity of two aspects of language - language in potentia (as a stable and static system of linguistic categories) and language in praesentia (real functioning of language, with its flexible, creative nature coming to the fore). The former, according to Baudouin de Courtenay, cannot exist unless it is immersed in the ever-going process of linguistic activity. The latter is the true reality of language where it is realized, changed and improved by its speakers [1]. The view of language as a phenomenon inseparable from human speech activity presupposes such properties of the language system as functional flexibility and potential dynamism, otherwise it would not be able to meet the needs of language functioning that is inherently creative. On the other hand, assuming that the system of language is not rigidly fixed but is subject to change, it logically entails a regulated, if not systemic, quality of the recurrent linguistic change, because fully arbitrary, chaotic innovation would not build into the system.

A more fundamental rationale in favour of linguistic creativity as a systemic phenomenon is provided from the standpoint of cognitive and discursive linguistics. One of the basic assumptions relevant to the present research is the understanding of language as an important instrument employed in human cognitive processes, such as categorization and conceptualization (N.N. Boldyrev, E.S. Kubryakova, R. Langacker, A. Wierzbicka etc). The mere fact that language facilitates thought and serves to form knowledge structures bears record to the order and system of the linguistic process itself - due to the order and system of human consciousness. It is widely acknowledged that we process and interpret new information relying on ready-made schemas and our mind's capacity for categorization, association, and modelling [2]. Accordingly, any innovations in language/lexis, particularly signs of secondary nomination, are preceded and stipulated by the transformations of the existing mental constructs $[2,3]$ and reflect the results of the new experience structuring.

Another important premise of the research is that at the linguistic level proper, the innovative processes are regulated by the norms of the given language and depend on the fund of the nominative means and patterns the language system contains [4]. Among the language tendencies underlying the renovation of the English lexical system, two deserve special attention: the tendencies towards economy and regularity. These now account for the growing productivity of secondary nomination in lexis (predominantly metaphor and analogy) and tertiary nomination in phraseology (largely non-conventional modifications of idioms and set phrases, as well as various types of derivation) [4].

\subsection{Methodology}

Since the subject of the research encompasses a variety of issues concerning lexical creativity and neology, analogy in language, metaphor, cognitive semantics and some others, preference is given to an integrative approach that makes it possible to combine diverse methods and research tools: apart from the traditional linguistic methods of sampling, definitional and semantic analyses, the study also employs methods of cognitive modelling, as well as techniques proposed by corpus linguistics and construction grammar.

The research is based on extensive empirical material comprising English analogybased metaphorical neologisms selected from various lexicographic sources, as well as 
nonce words and phrases built on particular patterns of analogy and registered in Englishlanguage corpora. Preference has been given to the British National Corpus (BNC).

\section{Major results of the study}

Firstly, a massive survey of various lexicographic sources has substantiated the assumption that the predominant number of English lexical innovations result from a secondary nomination, i.e. the new units have been derived from conventional ones - largely by analogy or via metaphorization (or involving some other trope); some cases display a combination of both mechanisms of derivation. Secondly, the neologisms and nonce words/phrases registered are not miscellaneous coinages or anomalous distortions of normative units, for they fit into certain nominative patterns existing in English.

Analogy appears to be a universal means of generating/coining and simultaneously normalizing lexical novelties, which makes it one of the basic principles of language evolution [5]. Analogy enables the speaker to make use of the available linguistic forms for creating new ones - through their new combination in accordance with a certain model or pattern [6]. This is possible due to the fact that analogy is a cognitive and linguistic phenomenon simultaneously. Using a conventional language sign/form for coining on its basis a novel word/phrase, the speaker proceeds from assumed similarity of two concepts, so that one of them can be interpreted and conveyed through the other - if it is adjusted to fit the new content. Such modifications of the original mental structure are usually represented in the modified form of the corresponding language unit. For example, the neologism snail mail was coined by analogy with the term electronic mail. Obviously, the new conceptual content conveyed by the neologism is associated with the left-hand component of the phrase - snail that symbolizes slowness and procrastination. This zoological metaphor serves to represent modern man's idea of the traditional mail service as opposed to email.

Being a highly economical nominative means, analogy permits using for a new nomination part of the prototype's form. In case of compounds and phrases, it is the construction that remains unaffected by the modification. (Here, 'construction' is treated as a unity of a syntactic structure and the meaning of the unit it conditions; for instance, in [7]). A corpus-based study shows that the original construction is reproduced without any changes in all new coinages formed by analogy, which accounts for their perception as modifications of the conventional lexical unit (prototype). This fact makes it possible to decipher their meanings, even if their lexical composition differs a lot from that of the original phrase. For example, the variation of the idiom golden hello (a generous payment or gift to a prospective employee in order to encourage him/her to join the company) admits a wide range of lexical substitutions (golden handshake / handcuffs / parachute etc; platinum / diamond handcuffs; brass/silver safety-belt; tin parachute and so on) - with the construction intact, which enables the language speakers to identify the derivatives of the original idiom, including its nonce variants designed for a single, specific use.

The given illustration demonstrates schematicity of the mechanism of analogy, for it is an illuminating case of 'serial' generation of analogical units on the basis of one conventional prototype. The ability of analogy to replicate the construction of the prototype, filling in the slots with new lexical components, and generate a series or cluster of new units with predetermined properties explains the common employment of analogy for replenishing the lexical system. Here, it is also important to point out the regulating function of analogy which permits to streamline the process of forming new units and integrate newly coined words/phrases in the system.

Analogy is efficient both in generating new units according to regular derivational models and in creating individual novel expressions on the basis of particular prototypes ('coining' in 
Ch. Fillmore's terms). Anyway, the pattern of analogy in every case rests on a certain variation model that is designed by a sample of the prototype's construction coupled with the invariant conceptual structure underlying its conventional meaning [8]. This model defines the vector and boundaries of every unit's potential variation and makes it possible to forecast the properties of the would-be coinages.

The stated schematicity of units formed by analogy implies a rigid algorithm-like schema in accordance with which the prototype is transformed in case of a creative use of a conventional unit. Thus, all the derivatives of the idiom golden hello are metaphorical phrases built on the $\mathrm{N}+\mathrm{N}$ pattern, with the left-hand component $\mathrm{N} 1$ designating a metal (sometimes a mineral) that is accepted as a standard of a particular value (e.g. 'platinum' and 'diamond' connote a higher value of something as compared to 'gold' or 'silver', let alone 'tin'); the second components of such phrases is a noun with a broader meaning that renders the idea of welcoming/parting or certain circumstances allied with welcoming/parting (e.g. 'safety-belt' and 'parachute' serve to represent safety, like in the neologism golden parachute - a contract according to which a worthless employee cannot be relieved of his/her post without a generous compensation). So, the algorithm of change that is to adapt the conventional unit to the speaker's new intent is clear enough to infer the actual meaning of every new coinage formed on the stated pattern of analogy.

In the collocations helicopter parent(s)/parenting and lawnmower parent(s)/parenting the right-hand component is realized in its literal meaning, whereas the other is metaphorically transferred, with the image depicting a style of parenting. Both expressions stand for excessive patronizing of children. The former, through the image of a helicopter, describes parents that keep supervising their children all the time, never leaving them to their own devices; the second unit rests on the image of a lawnmower and via this metaphor portrays the kind of patronizing parents who try to remove every obstacle off their children's way and make their life absolutely carefree and effortless. The algorithm of change applied here admits a wide range of substitute words, including zoological metaphors with a conventionalized symbolic meaning (e.g. alpha dog parent / alpha mom; tiger parent/mom etc). In fact, it allows any word that can serve to represent a standard of a particular quality associated with parenting. This makes the analogy pattern employed here highly transparent.

However, in some cases, especially in dealing with idioms or idiomatic compounds, the algorithm is not so clear as the mechanism of transfer (metaphor) may be complicated by cultural knowledge. For instance, the neologism quiche-eater (a timid or excessively gentle, sensitive man, one who is seen by others as devoid of true manliness) obviously has been formed by analogy with such conventional units as fire-eater (1. a street entertainer who performs tricks with fire to impress the public; 2. a brutal, bullying man, spitfire) and lotuseater (an idle dreamer, one out of this world). In all the three cases, adequate interpretation of these words requires special knowledge, so their idiomatic meanings cannot be fully inferred from the meanings of their lexical components (root morphemes) or from the construction that underlies these compounds. However, the construction makes a pattern that at least partially clarifies the integrated meaning of each word and can be regularly employed to coin novel units by analogy: $\mathrm{N}$ (root morpheme) + -eater $=$ a particular kind of person, usually male. The first slot/root morpheme is to be filled with a noun literally designating something "eatable" and at the same time possessing a symbolic meaning conventionally accepted in the English-speaking culture.

Obviously, in cases like the one cited above, knowledge of the relevant cultural information is essential to proper comprehension of a new unit. However, the productivity of a pattern, as well as the clarity of the algorithm involved, often suffices to correctly interpret the actual meaning of a neologism formed on this pattern. For instance, the openend series of English neologisms: rainbow alliance/family/society etc with the constant 
component rainbow connotes the idea of multiculturalism, with diversity of all kinds welcomed. This general meaning of the series goes back to the biblical symbolism of rainbow as an omen of God's grace and an emblem of man's reconciliation with God. In modern European culture, this ancient symbol has been recontextualized and now serves as a metaphor of tolerance. Exactly this interpretation of the rainbow lexeme has given rise to a number of noun-phrases, with the right-hand component, a collective noun, designating a kind of community or group of persons. So, the resultant meaning of the phrases based on the given construction is that of a unity of people embracing diversity and otherness. The clear algorithm and regularity of analogy-based coinages well manifested in the given series make the knowledge of background cultural information supplementary: the actual meaning of every newly formed phrase is decoded by analogy with the more familiar units that already exist in a person's thesaurus.

Sometimes the algorithm of variation proceeds from a conceptual metaphor model. Thus, there is a pattern of analogy in English phraseology that is represented by numerous expressions with a shared meaning of an extremely difficult or dangerous situation: to be in a jam / a creek / a kettle of fish / a hole / a tight corner / dire straits etc. All of these idiomatic expressions fit in with the basic metaphor of CONTAINER verbalized by means of a construction with the preposition in and a noun that metaphorically connotes a constrained condition, with motion either impossible or handicapped. The conceptual metaphor model underlying these idioms factually provides a limitless, open-ended series of analogical units with the variable slot being filled with any noun that may render the idea of a physical constraint.

In a similar way, a number of English verbal phrases with the verb to go serve to represent the concept of decline, devastation, or death: to go down/downhill, go bust/broke, go phut, go wrong, go west etc. Among them, based on the same pattern, though probably less known is the American idiom to go south. Regardless of its true etymology, it definitely tallies with the other units of this analogical series - both from the angle of purely linguistic features (construction, lexical-grammatical pattern, meaning) and in terms of the conceptual structure. Besides, if you follow a geographical map, 'going south' literally represents the downward direction, which can be seen as manifestation of the conceptual metaphor model DOWN is BAD represented in numerous figurative expressions such as the abovementioned to go down/downhill, as well as to feel down, someone's spirits/heart sank/went down, to be down on someone, be down on one's luck etc.

On the other hand, the American idiom may well have been formed directly by analogy with its British counterpart to go west which has an equivalent meaning: BrE "die, perish, be lost [from the sun sinking in the west]" [9]. The two units are characterized by visible similarity of form - both of them, in fact, rest on the same construction and, moreover, display an exactly identical model of variation with a more rigid algorithm of lexical substitution as opposed to their synonyms. In this case, the final component of either idiom can be filled by a noun designating the compass points. Apart from it, the Americanism "inherited" from the British prototype not only its construction, including the lexical and grammatical composition, but also the mechanism of transference, which presents an essential feature of idiomatic units based on analogy. The crucial factor here is the derivational connection of the units, which provides immediate access to the relevant knowledge. As a result, the respective conceptual schemas are easily identified, and the derivative is perceived as motivated.

However, imbued with a specific cultural content that reflects a different extra-linguistic background, the idiom to go south displays a national "flavour". Only the shift is not so significant as to impair the derivational connection of the two units. Anyway, it is evident that the analyzed coinage is far from being a spontaneous individual creation - rather it 
arose from a complicated network of semantic and cultural implications, as well as on the basis of a particular analogical pattern available in the language system.

\section{Conclusion}

Summing up, it is necessary to point out the following. The analysis of massive empirical data provided by various lexicographical sources and corpora reveals an obviously regimented and systematic quality of lexical innovations in modern English. A major regulating factor here is the principle of analogy. Remarkably, it displays a balance of two differently directed tendencies: on the one hand, analogy conditions and even provokes all kinds of structural or/and semantic innovations and makes it possible to build the new phenomena into the system; on the other hand, it restricts the dynamism of the language, thus protecting the system from self-destruction, which uncontrolled modification might cause.

A schematic, algorithm-like quality of the formation of novel lexical/idiomatic units by analogy facilitates the identification of the new coinages (both by traditional means and employing new, computer-assisted techniques, including automated search). What is most important, identification of algorithms involved in the generation or coining of new units by analogy permits to model the properties of the neologisms and individual coinages that already exist. Moreover, due to this fact, it is possible to forecast innovations to be introduced in certain segments of the lexical system in the future.

These conclusions seem to be equally important both for academics and common users of language. In the former case, the findings may help scholars to develop more efficient research tools for studying innovations in English. But it is probably even more important that insights into the regularities of lexical change makes it possible for every speaker of language to keep track of the rapid and kaleidoscopic process of language renovation in our cyber age.

\section{Acknowledgments}

This paper was financially supported by the Russian Foundation for Basic Research, grant No. 20-012-22046.

\section{References}

1. I.A. Baudouin de Courtenay, Selected works in linguistics, Vol. 1 (1963)

2. L.V. Babina, Cognitive foundations for secondary phenomena in language and speech (2003)

3. R. W. Langacker, Foundations of cognitive grammar, Vol. 1 (1987)

4. E.V. Ryzhkina, On phraseological neology: Regularity vs. creativity (based on modern English phraseology), in Proceedings of the 12th Conference of the European Society for the Study of English, Pavol Jozef Šafárik University, 29 August - 2 September 2014, Košice, Slovakia (2014). Retrieved from: http://kaa.ff.upjs.sk/en/event/4/12th-esseconference\#toc-linguistics

5. G.G. Bondarchuk, L.V. Yarotskaya, E.O. Shevelyova, Analogy in language: Theory and educational practice (2018)

6. E.S. Kubryakova, Analogy, Linguistics, Big linguistic dictionary, 31-32 (1998)

7. Ch. J. Fillmore, P. Kay, C. O’Connor, Language, 64. No. 3, 501-538 (1988) 
8. E.V. Ryzhkina, Messenger of MSLU, Humanities, 13 (807), 245-258 (2018)

A.P. Cowie, R. Mackin, I.R. McCaig, The Oxford Dictionary of Current Idiomatic English (1994) 